Official Journal of the Neuroscience Society of Nigeria (NSN)

\title{
Influence of Antidepressant Medication on Short Term Memory in Chronic Mild Stress Mouse Model of Depression
}

\author{
Saeed Mustapha ${ }^{1}$, Majidat Y. Oshafu ${ }^{2}$, Umar M. Adam ${ }^{2}$, \\ Yusuf Yusha'u², Abubakar B. Daku' \\ ${ }^{1}$ Department of Human Physiology, Faculty of Basic Medical Sciences, Federal University, Dutse, Nigeria \\ ${ }^{2}$ Department of Human Physiology, Faculty of Basic Medical Sciences, Ahmadu Bello University, Zaria, Nigeria
}

Received:

October 2020

Accepted:

January 2021

\begin{abstract}
Depression is among the most prevalent diseases worldwide. Researchers have identified a link between depression and different types of memory loss, including short term memory (STM). Also, the memory impairment in depression is a function of severity. This study was conducted to evaluate the effect of antidepressant medication on short term memory in chronic mild stress (CMS) mouse model of depression. A total of eighteen female mice were randomly divided into three groups of six mice each $(n=6)$. Group I served as normal control, group II were exposed to CMS for 14 days, group III were exposed to CMS for 14 days, and thereafter treated with paroxetine at a dose of $20 \mathrm{mg} / \mathrm{kg}$ for 14 days. Short term memory was assessed using batteries of cognitive tests including the Y-maze and novel object recognition. Further antidepressant effect was measured using the tail suspension test (TST). The results showed that paroxetine at $20 \mathrm{mg} / \mathrm{kg}$ significantly improved the short term memory of the depressed female mice $(p<0.05)$ in the $Y$-maze and novel object (recognition) tasks after CMS. Therefore, paroxetine might be used to enhance short term memory in depressed individuals, although clinical studies are required to confirm this finding.
\end{abstract}

Key words: Depression, Antidepressant (Paroxetine), Short-term memory

\section{INTRODUCTION}

Depression is a common neuropsychiatric disorder characterized by change in mood, lack of interest in pleasurable activities (anhedonia), weight gain, sleep problems like insomnia, fatigue, feeling of worthlessness, difficulty in concentration and suicidal thought. Symptoms have to persist for more than two weeks for an individual to be diagnosed with depression (Moledina et al. 2018). Depression is a debilitating cluster of symptoms that may persist for a period of weeks, months or even years (Dabana and Gobir 2018). Clinically, depressions is characterized by anhedonia, sleep disturbances, reduced food intake, decreased locomotor activity, increased sensitivity to pain and deficits in cognition and energy (Knapen et al. 2009; Liu, et al. 2016). Depression is among the most prevalent disease worldwide. It is estimated that by 2030 depression related morbidity rates will rise, and depression as one of the leading causes of disability will increase significantly in the total burden of disease (Milanovic et al. 2015). Depression affects more than 168 million people worldwide and is one of the major causes of disease burden, accounting for the fifth highest global years lived with disability. It is also one of the key factors for impaired quality of life in patients with chronic diseases (Lee and Giuliani 2019). The main symptoms of depression are due to functional deficiency in the level of monoaminergic neurotransmitters like norepinephrine (NE), 5-

Correspondence: Saeed Mustapha, MSc, Department of Human Physiology, Faculty of Basic Medical Sciences, Federal University, Dutse, Nigeria. almustaeed2@gmail.com, $+2348062608288$ 
hydroxytryptamine (5HT) and dopamine (DA) in the brain (Carlson 2005). Factors associated with major depression, according to a study, are lack of education, being unmarried, and being unemployed (Ademola et al. 2019). Depression, considered as the most common psychological problem in individuals often lead to cognitive impairment due to a reduced level of neurotransmitters that control mood in the brain (Walia 2017). Paroxetine, a type of highly selective 5-hydroxytryptamine (5-HT) - reuptake inhibitor, inhibits 5-HT reuptake in synapses and increase their nerve conduction rate, exerting antidepressant effects (Han et al. 2015). Cognitive disturbances are often reported as serious incapacitating symptoms by patients suffering from major depressive disorders (MDDs). Such deficits have been observed in various animal models based on environmental stress (Darcet et al. 2014). Depression and cognitive impairment are considered as part of the major neurological disorders in the world. It was found that long-term therapy with certain antidepressants may also be linked to cognitive side effects in adult subjects with Major depressive disorder (MDD) (Bortolato et al. 2016). Neuroimaging studies have found that depressed patients show structural and functional changes (such as promoting transporter proteins for uptake of monoamines and irregularities in neurotransmission) in brain structures critical for learning and memory, such as the prefrontal cortex, hippocampus and the amygdala (Zarate et al. 2006; Yu et al. 2011). However, the neurobiological underpinnings of cognitive deficits in depression remain poorly understood. Some studies have shown that classic antidepressant drugs can effectively increase cognitive function (Outhred et al. 2013), however, the effect of antidepressant medication on spatial and non-spatial short-term memory in experimental mouse model of depression remained to be determined. Thus, the aim of this study was to evaluate the cognitive enhancing effect of anti-depressant medication on mouse model of depression.

\section{MATERIALS AND METHODS}

Drug Preparation and Administration

Seroxat (paroxetine hydrochloride) $20 \mathrm{mg} / \mathrm{kg}$ was purchased from TEVA Limited, United Kingdom, Eastbourne, BN229AG (Licence number: PL00289/0521; Batch number: 83730-V; LOT number: 014123$)$. Ten milligram of the seroxat was dissolved in $5 \mathrm{~mL}$ of distilled water, to prepare a stock concentration of $2 \mathrm{mg} / \mathrm{mL}$. The mice were weighed using weighing balance and the seroxat was administered orally in a volume equal to their body weight using $1 \mathrm{~mL}$ syringes and cannulas. The treatment was performed once daily between 8:00 a.m. to 10:00 a.m. In previous studies conducted (Kantor et al. 2017), the effective dose of paroxetine that did not induce sedation was found to be 20 $\mathrm{mg} / \mathrm{kg}$.

Table 1: Tail suspension test schedule

$\begin{array}{lcc}\prod_{\text {CMS period }} \prod_{\text {week }} & \text { CMS + treatment period } \\ \text { TST } & \text { 2 weeks } & \\ \text { TST } & 4 \text { weeks } \\ \text { TST }\end{array}$

Key-TST: tail suspension test, CMS: chronic mild stress

\section{Animals}

Eighteen female healthy adult Swiss albino mice weighing 18-25 $\mathrm{g}$ were used for the studies. They were obtained from the Animal House, Faculty of Pharmaceutical Sciences, Ahmadu Bello University (A.B.U) Zaria-Nigeria. They were housed individually in plastic cages containing sawdust bedding and fed with pellets made from grower's mash, maize offal as binder and access to water ad libitum. All efforts were made to minimize animal suffering and to reduce the number of animals used. All the experimental procedures on animals were in accordance with regulation on the care and use of laboratory animals (NIH, 1996) and Ahmadu Bello University research policy.

Animal groupings: The mice were randomly assigned into three groups of six animals each as follows: Control, kept under normal conditions with free access to food and tap water; CMS mice were exposed to chronic mild stress to induce depressive like symptoms for 14 days; CMS + Paroxetine: The mice were post-treated with $20 \mathrm{mg} / \mathrm{kg}$ of seroxat

Table 2: Chronic Mild Stress Schedule

\begin{tabular}{|c|c|c|c|c|c|c|c|c|c|c|c|c|c|c|}
\hline Days & $\begin{array}{c}\text { Mon } \\
1\end{array}$ & $\begin{array}{c}\text { Tue } \\
2\end{array}$ & $\begin{array}{c}\text { Wed } \\
3\end{array}$ & $\begin{array}{c}\text { Thu } \\
4\end{array}$ & $\begin{array}{c}\text { Fri } \\
5\end{array}$ & $\begin{array}{c}\text { Sat } \\
6\end{array}$ & $\begin{array}{c}\text { Sun } \\
7\end{array}$ & $\begin{array}{c}\text { Mon } \\
8\end{array}$ & $\begin{array}{c}\text { Tue } \\
9\end{array}$ & $\begin{array}{c}\text { Wed } \\
10\end{array}$ & $\begin{array}{c}\text { Thu } \\
11\end{array}$ & $\begin{array}{l}\text { Fri } \\
12\end{array}$ & $\begin{array}{l}\text { Sat } \\
13\end{array}$ & $\begin{array}{c}\text { Sun } \\
14\end{array}$ \\
\hline $\begin{array}{l}\text { Morning } \\
\text { session }\end{array}$ & $\begin{array}{l}\text { TC } \\
2 \mathrm{~h}\end{array}$ & $\begin{array}{l}\text { DS } \\
1 \mathrm{~h}\end{array}$ & $\begin{array}{l}\text { EC } \\
3 \mathrm{~h}\end{array}$ & $\begin{array}{l}\text { SS } \\
3 \mathrm{~h}\end{array}$ & $\begin{array}{l}\text { EW } \\
2 \mathrm{~h}\end{array}$ & $\begin{array}{l}\text { EC } \\
3 \mathrm{~h}\end{array}$ & $\begin{array}{l}\mathrm{NC} \\
4 \mathrm{~h}\end{array}$ & $\begin{array}{l}\mathrm{TC} \\
2 \mathrm{~h}\end{array}$ & $\begin{array}{l}\text { WN } \\
6 \mathrm{~h}\end{array}$ & $\begin{array}{l}\text { SS } \\
3 \mathrm{~h}\end{array}$ & $\begin{array}{l}\text { PS } \\
1 \mathrm{~h}\end{array}$ & $\begin{array}{l}\text { EC } \\
3 \mathrm{~h}\end{array}$ & $\begin{array}{l}\mathrm{NC} \\
4 \mathrm{~h}\end{array}$ & $\begin{array}{l}\mathrm{TC} \\
2 \mathrm{~h}\end{array}$ \\
\hline $\begin{array}{l}\text { Evening } \\
\text { session }\end{array}$ & $\begin{array}{l}\text { PS } \\
1 \mathrm{~h}\end{array}$ & $\begin{array}{l}\text { WN } \\
6 \mathrm{~h}\end{array}$ & $\begin{array}{l}\text { OI } \\
12 \mathrm{~h}\end{array}$ & $\begin{array}{c}\text { DS } \\
1 \mathrm{~h}\end{array}$ & $\begin{array}{l}\text { WN } \\
6 \mathrm{~h}\end{array}$ & $\begin{array}{l}\mathrm{OI} \\
12 \mathrm{~h}\end{array}$ & $\begin{array}{l}\text { SS } \\
3 h\end{array}$ & $\begin{array}{l}\text { PS } \\
1 \mathrm{~h}\end{array}$ & $\begin{array}{l}\text { EC } \\
3 h\end{array}$ & $\begin{array}{l}\text { DS } \\
1 \mathrm{~h}\end{array}$ & $\begin{array}{l}\text { WN } \\
6 \mathrm{~h}\end{array}$ & $\begin{array}{c}E W \\
2 h\end{array}$ & $\begin{array}{c}\mathrm{OI} \\
12 \mathrm{~h}\end{array}$ & $\begin{array}{l}\text { PS } \\
1 \mathrm{~h}\end{array}$ \\
\hline
\end{tabular}

TC: Tilted cage, DS: Dam sawdust, EC: Empty cage, SS: Social stress, EW: Empty cage + water, NC: New clean cage, PS: Predator sound, OI: Overnight Illumination, WN: White noise. 
(paroxetine) for 14 days, after inducing depressivelike behaviours by chronic mild stress (Kantor et al. 2017; Yusha'u et al. 2019).

Mice were brought to the neurobehavioural room, 30 min before each of the behavioural test to allow acclimatization to the test room.

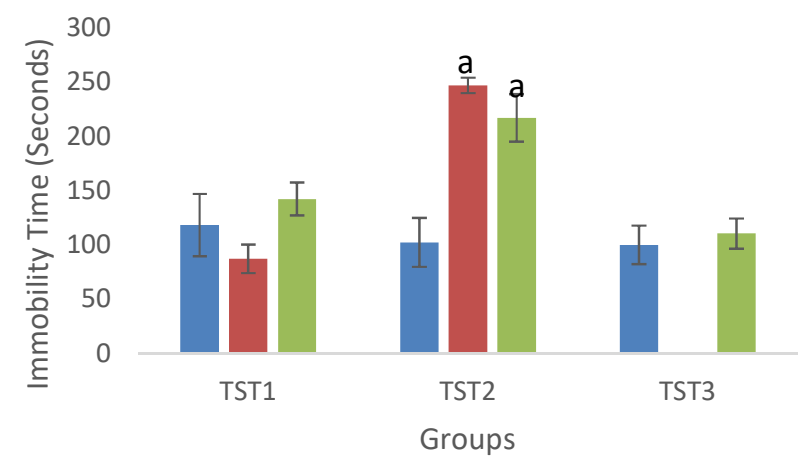

- Control $\square \mathrm{CMS} \square$ "CMS + paroxetine

Fig. 1: Immobility time of CMS-induced depressed mice. $(n=6)$. CMS increased behavioural despair compared to control group in TST $2(p<0.05)$. Results presented as Mean \pm SEM. CMS: chronic mild stress, TST1: Tail suspension test before depression, TST2: Tail suspension test after depression, TST3: Tail suspension test after treatment. ${ }^{a}$ Statistically significant compared to control group

Assessment of Behavioural Despair using Tail Suspension Test (TST)

The tail suspension test is a well characterized test for assessing depressive-like and antidepressant-like activity (Cryan et al. 2003). The test was carried out essentially as described by Steru et al. (1985) with slight modifications. Mice were brought into the neurobehavioural laboratory $30 \mathrm{~min}$ prior to testing for acclimatization. The testing room was kept in normal lighting during the test. Adhesive tape $(17 \mathrm{~cm}$ in length) was marked at $2 \mathrm{~cm}$ of both ends. The tail of the mouse was tightened at $2 \mathrm{~cm}$ from one end living approximately $1 \mathrm{~mm}$ from the tip of the tail, while the other end was suspended on the suspension bar $(1 \mathrm{~cm}$ height $\times 1 \mathrm{~cm}$ width $\times 60 \mathrm{~cm}$ length). The suspension box (made of wood with the dimension 55 heights $\times 60$ widths $\times 12 \mathrm{~cm}$ depth) was wiped thoroughly after each session with $70 \%$ ethanol to prevent olfactory cues. A climbing stopper $(4 \mathrm{~cm}$ length, $1.6 \mathrm{~cm}$ outside diameter, $1.3 \mathrm{~cm}$ inside diameter) was used to prevent the animal from tail climbing during the experiment. Each animal under study was isolated from other animals during the test. Each mouse was suspended in the middle of the compartment in which the width and depth were sufficiently sized so that the mouse cannot contact the walls. Further, the approximate distance between the mouse's nose and the apparatus floor was 20-25 $\mathrm{cm}$. The test was conducted for $6 \mathrm{~min}$ and immobility was measured during the last $4 \mathrm{~min}$, using a stopwatch. TST was conducted before inducing depression, after inducing depression and .posttreatment with anti-depressant medication. Depression was induced using CMS.

\section{Induction of Depression using Chronic Mild Stress Mouse Model}

The CMS regimen used in this study was based on the procedure originally designed by Willner (1997) and adopted to mice by Ducottet et al. (2003). Briefly, mice were exposed to different stressors such as; empty caging, empty caging with $100 \mathrm{~mL}$ of water, new clean cage, soiled caging, tilted caging at an angle of $45^{\circ}$, social stress (switching cages), predator sounds for $30 \mathrm{~min}$ (meowing sound), overnight illumination, and white noise (static radio sound). These stressors were applied randomly in an unpredictable way for 14 days. Behavioural despair using TST was measured as outlined above in the TST section.

\section{Assessment of Working Memory using Y-Maze Model}

The Y-maze is a simple two-trial recognition test for measuring spatial recognition memory, it does not require learning of a rule, and thus, is useful for studying memory in rodents, and in particular for the

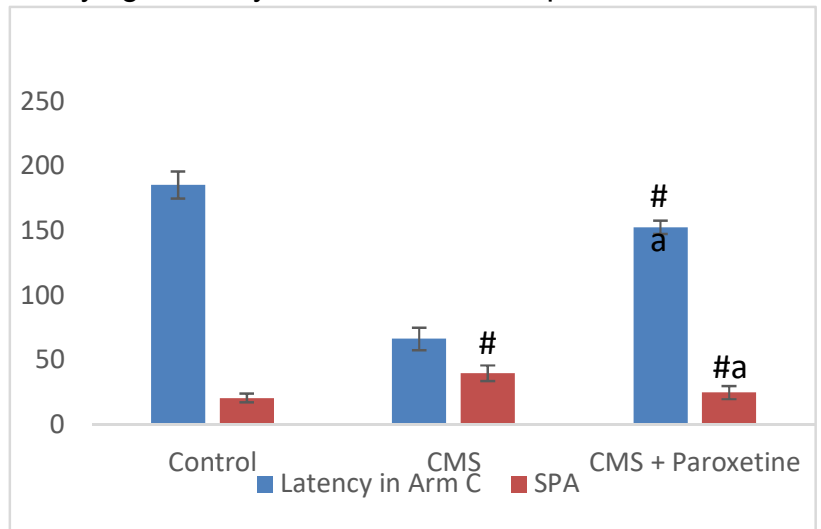

Fig. 2: Spatial short-term memory of mice. $(n=6)$. Paroxetine improved short-term memory of CMS-induced depressed mice $(p<0.05)$. Results presented as Mean \pm SEM. CMS: chronic mild stress, SPA: spontaneous alternations; \# Statistically significant when compare to control group; ${ }^{a}$ Statistically significant when compared to CMS group

study of genetic influences on the response to novelty and recognition processes (Vasundhara et al. 2013). Y-maze apparatus was made up of wood, consisting of three arms with an angle of $120^{\circ}$ between each of the arms. The two equal arms dimensions were $7 \times 15 \times 12 \mathrm{~cm}$ (width $\times$ length $\times$ height) and one longer arm $7 \times 20 \times 12 \mathrm{~cm}$. The three arms were randomly designated: start arm, in which the mouse started to explore (A), $(B)$, and the other arm (C) novel arm. On the first trial (training 
session), arm $C$ was blocked and mice were allowed to explore arms (A) and (B) for $5 \mathrm{~min}$. In the second trial (testing session), all arms are open and mice are allowed to explore the arms for $15 \mathrm{~min}$. The maze was disinfected with $70 \%$ ethanol between each animal to avoid influence of olfactory cue of the previous animal on the behaviour of the succeeding animal. Mice tend to explore the maze systematically, entering each arm in turn. The ability to alternate requires that the mice know which arm they have already visited. Alternation is defined as the number of successive entries into the three arms. This was done to all the three groups of normal control, chronic mild stress and the treatment groups. The number of visits to the novel arm (C) and number of alternations were manually scored by visual inspection.

\section{Assessment of Short-term Memory using Novel Object Recognition Test}

The apparatus used consists of opaque plastic measuring $42 \times 52 \mathrm{~cm}$. The walls were $40 \mathrm{~cm}$ high. It involves two phases: training and testing (Zhang et al. 2012). In the training phase, two identical objects were placed at opposite positions within the box at same distance from the nearest corner; mice were then allowed to freely explore the objects for $5 \mathrm{~min}$ and were then returned to their home cages. One hour later, the mice were placed back in the novel object recognition task (NORT) arena, where one of the two familiar objects was switched with a novel object, and here also animals were allowed to explore the objects for $5 \mathrm{~min}$. The objects used in this study were of the same shape and sizes, except in the novel object for the testing phase and were firmly fixed to prevent displacement. To preclude the existence of olfactory cues, the entire box and objects were always thoroughly cleaned with $70 \%$ ethanol after each trial. Object exploration time was

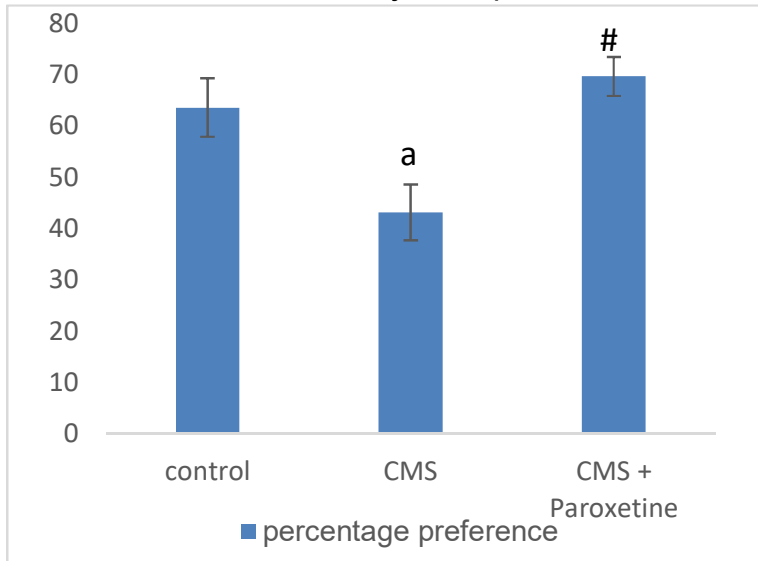

Fig. 3: Non-Spatial short-term memory of mice.. $(n=6)$. Paroxetine improved non-spatial short-term memory of CMSinduced depressed mice $(p<0.05)$. Results presented as Mean \pm SEM. CMS: Chronic Mild Stress, NORT: Novel object recognition test; * Statistically significant when compared with control group; \# Statistically significant when compared to CMS group defined as the length of time the animal directed its nose within $2 \mathrm{~cm}$ distance to the object or sniffing or pawing the object. Location preference and recognition index $(R \mathrm{R})$ during the testing phase was manually scored using a counter and a stopwatch.

\section{Statistical Analysis}

Data obtained were expressed as mean \pm SEM. One way analysis of variance was used to analyse means of behavioural scores for each of the three behaviours test followed by Turkey's post hoc for multiple comparison. Values with $p<0.05$ were considered statistically significant. Statistical analysis was performed using statistical package for social science (SPSS), version 22.0 for Windows.

\section{RESULTS}

Effect of Antidepressant Medication on Behavioural Despair using Tail Suspension Test in Chronic Mild Stress Mouse Model of Depression

The result obtained showed that there was no statistically significant difference in the immobility time (behavioural despair) before inducing depression between the groups $[F(2,15)=1.860, P$ $=0.19](P>0.05)$. However, there was a statistically significant difference in the immobility time (behavioural despair) between the groups [F $(2,15)$ $=16.90, p=0.000$ ] after inducing depression using CMS. Tukey's post hoc test comparison revealed that the immobility time of the control group (102.33 \pm 22.53) was significantly different from the depressed group (CMS) $(246.83 \pm 7.10)$, but there was no difference in comparison with the treatment group (CMS + paroxetine) after treatment.

Influence of Antidepressant Medication
(Paroxetine) on Short-Term Memory in Mice
Exposed to Chronic Mild Stress Model of
Depression
The result showed that there was a statistically between the groups $[F(2,15)=53.680, P=0.000]$. Tukey's post-hoc test comparison revealed that there was a statistically significant difference between the control (185.50 \pm 10.49$)$ and treatment group (152.67 $\pm 5.20)$, as well as the depressed group (66.33 \pm 8.64). There was also a significant difference when the treatment group $(152.67 \pm 5.20)$ was compared to the depressed group (66.33 \pm 8.64$)$.

Furthermore, in the spontaneous alternation (SPA), the result showed that there was statistically significant difference between the groups $[F(2,15)=$ 5.994, $P=0.012]$. The Tukey's post hoc test comparison revealed that there was a statistically significant difference between the control (20.33 \pm $3.33)$ and treatment groups $(24.58 \pm 5.00)$, as well as the depressed group $(39.64 \pm 6.02)$. There was also 
a statistically significant difference between the treatment $(24.58 \pm 5.00)$ and depressed groups (39.64 \pm 6.02$)$.

\section{Influence of Antidepressant Medication (Paroxetine) on Short-term Memory Using Novel Object Recognition Test in Mice Subjected to Chronic Mild Stress Mouse Model of Depression}

Turkey's post hoc test comparison revealed that there was statistically significant difference with the depressed group (43.14 \pm 5.42$)$ compared with the control $(63.58 \pm 5.68)$. There was also a significant mean difference when the treatment group (69.63 \pm 3.76) was compared to the depressed group (43.14 \pm $5.42)$.

\section{DISCUSSION}

According to the World Health Organization (WHO), the global prevalence of depression is $4.4 \%$ with approximately 322 million people living with depression (Abdelhalim et al. 2019). Depression may cause short term memory loss. A 2018 study found that memory complaints had correlation with more severe symptoms of depression in people (Schweizer et al. 2018). This study was carried out to evaluate the influence of paroxetine (seroxat) an antidepressant medication on short term recognition memory in depressed mice. The result obtained on the effect of antidepressant medication on immobility time (behavioural despair) indicates a significant increase in immobility time for the depressed mice after undergoing chronic mild stress (CMS) when compared to the control group, whereas those treated with paroxetine showed a decrease in the immobility time. This further confirmed that the drug (paroxetine) has antidepressant activity. The extent of immobility is thought to be associated with the depressive-like behaviour of the mice and is diminished significantly by antidepressant paroxetine, which is similar to the report of Aslam (2016) and Walia (2016) that antidepressant drug, fluoxetine reduced the immobility period of stressed mice in tail suspension test. This is contrary to the study of Bali et al. (2016), which showed no statistically significant effect of paroxetine on the elderly with depression.

The results of the Y-maze test showed a significant relationship between depression and working memory in mice. The working memory was attenuated or decreased by induction of depression through chronic mild stress when compared to the control. This result coincides with Lauer et al. (1994) and Schweizer et al. (2018) who reported that highly depressed patients demonstrated performance deficit relative to non-depressed and low depressed on auditory verbal learning test; stressing that memory impairment in depression varied as a function of severity. Depression is proposed to often lead to cognitive impairment due to a reduced level of brain neurotransmitters, especially serotonin that control mood (Walia 2017). Paroxetine enhanced the working memory in mice as reflected in this study for time spent in arm C in the CMS + Paroxetine group, which is in accordance with study of Han et al. (2015), who reported that paroxetine improves memory and learning functions in rat a model of depression. This can be explained by the action of antidepressants to centrally normalize levels of neurotransmitters like serotonin in the prefrontal cortex and the amygdala.

The results of novel object recognition test revealed that cognition in the mice was decreased (on comparison with control) after depression by CMS. Moreover, there was also a significant increase in percentage preference after treatment with paroxetine. This result coincides with findings of Elizalde et al. (2008) which states that mice exposed to CMS displayed impaired memory in NORT, while paroxetine treatment reverted the impaired recognition memory and the long term effects of CMS were partially prevented by chronic paroxetine (10 $\mathrm{mg} / \mathrm{kg} / \mathrm{day}$ ). This may be explained by the fact that cognitive impairments associated with depression affect the brain with an emphasis on various aspects of executive function such as memory, attention, as well as problem-solving. These deficits are related to patterns of brain activity observed in prefrontal cortex, amygdala, hippocampus and parts of the anterior cingulate cortex in the experience of emotional state and depression (Gotlib and Joormann 2010), The test also revealed that application of antidepressant medication increased the cognition in mice when compared to both the controls and the depressed group. Therefore, this is an indication of a positive influence of the selective serotonin reuptake inhibitors (SSRI), paroxetine on learning and memory in depressed mice. This is probably due to the effect of antidepressant medication like paroxetine to increase the concentration and availability of the monoamines; serotonin, norepinephrine and dopamine in the brain areas like the prefrontal cortex, dorsal raphe nuclei, amygdale and hippocampus, by inhibiting the action of transporter proteins for re-uptake of these monoamines in such brain areas. Others like ketamine an N-methyl-D-aspartate receptor antagonist also restored normal levels of glutamate in regions of the brain like hippocampus, amygdala, caudal putamen and dorsal raphe. Antidepressant medications tend to repair irregularities in neurotransmission in those brain areas concerned with cognition and memory, which are impaired by depression (Zarate et al. 2006).

\section{Conclusion}

From the study, depression decreases cognition. However, antidepressant medication, paroxetine, a 
form of selective serotonin reuptake inhibitors (SSRIs) enhanced both spatial and non-spatial short term memory in depressed mice.

\section{Conflict of Interest}

None declared.

\section{REFERENCES}

Abdelhalim, A., Khan, I. and Karim, N (2019) The Contribution of ionotropic GABAergic and $\mathrm{N}$-methyl-D-Aspartic acid receptors in the antidepressant-like effects of hispidulin. Pharmacognosy Magazine. 15(62):562-570.

Ademola, A.D., Boima, V., Odusola, A.O., Agyekum, F., Nwafor, C.E. and Salako, B.L. (2019) Prevalence and determinants of depression among patients with hypertension: a cross-sectional comparison study in Ghana and Nigeria. Nig J Clin Practice. 22(4):558565.

Aslam, M. (2016) Tail suspension test to evaluate the antidepressant activity of experimental drugs, Bang $\mathrm{J}$ Pharmaceuticol. 11:292-294

Bali, V., Chatterjee, S., Johnson, M.L., Chen, H., Carnaham, R.M. and Aparasu, R. (2016) Risk of cognitive decline associated with paroxetine use in elderly nursing home patients with depression. Am J Alzheimer's Dis Dementias. 31(8):1-9.

Bortolato, B., Miskowiak, K.W., Köhler, C.A., Maes, M., Fernandes, B.S., Berk, M., et al. (2016) Cognitive remission: a novel objective for the treatment of major depression? BMC Medicine. 14:9.

Carlson, N.R. (2005) Foundations of Physiological Psychology (6th Ed.). Boston: Pearson A and B. p.108.

Cryan, J.F., Kelly, P.H., Neijt, H.C., Sansig, G., Peter, J. and Flor, P.J. (2003) Antidepressant and anxiolytic-like effects in mice lacking the group iii metabotropic glutamate receptor mGluR7. Eur J Neurosci. 17:2409-2417.

Dabana, A. and Gobir, A.A (2018) Depression among students of a Nigerian university: prevalence and academic correlates. Archi Med Surg. 3(1):6-10.

Darcet, F., David, I.M., Tritschler, L., Gardie, A.M., Guilloux, J. and David, D.J. (2014) Learning and memory impairments in a neuroendocrine mouse model of anxiety and depression. Frontiers Behav Neurosci. 8:136-149.

Ducottet, C., Griebel, G. and Belzung, C. (2003) Effects of selective non-peptide corticotropinreleasing factor receptor 1 antagonist antalarmin in chronic mild stress model of depression in mice. Prog Psychopharmacol Biol Psychiatry. 27(40):625-631. Elizalde, N., Gil-Bea, F.J., Ramirez, M.J. and Aisa, B. (2008) Long-lasting behavioural effects and recognition memory deficit induced by chronic mild stress in mice: effect of antidepressant treatment, Psychopharmacol. 199(1):1-14.
Gotlib, I.H. and Joormann. J. (2010) Cognition and depression: current status and future directions. Ann Rev Clin Psychol. 6:285-312.

Han, J., Wang, L., Bian, H., Zhou, X. and Ruan, S. (2015) Effects of paroxetine on spatial memory function and protein kinase expression in a rat model of depression. Exp Therapeut Med. 10(4):1489-1492. Kantor, S., Varga, J., Kulkarni, S. and Morton, A.J. (2017) Chronic paroxetine treatment prevents the emergence of abnormal electroencephalogram oscillations in Huntington's disease mice. Neurotherapeutics. 14:1120-1133.

Knapen, J., Vancampfort, D., Schoubs, B., Probst, M., Sienaert, P., Haake, P., et al. (2018) Exercise for the treatment of depression. Open Complementary Med J. 1:78-83.

Lauer, R.E, Giordani, B., Boivin, M.J., Halle, N., Glasgow, B., Allessi, N.E., et al. (1994) Effects of depression on memory performance and metamemory in children. $\mathrm{J}$ Am Acad Child Adolescent Psychiatry. 33(5):679-685.

Lee, C. and Giuliani, F. (2019) The role of inflammation in Depression and fatigue. Frontiers Immunol. 10:1696.

Liu, L., Zhang, Q., Cai, Y., Sun, D., He, X., Wang, L., et al. (2016) Resveratrol counteracts lipopolysaccha ride-induced depressive like behaviors via enhanced hippocampal neurogenesis. Oncotarget. 7(35):5604556059 .

Milanovic, S.M., Erjavee, K., Poljicanin, T., Vrabee, B. and Brecia, P. (2015) Prevalence of depression, symptoms and associated socio-demographic factors in primary health care facilities. Psychiatria Danubina. 27(1):31-37.

Moledina, S.M, Bhimji, K.M. and Manji, K.P. (2018) Prevalence and associated factors of depression in an Asian community in Dar es Salaam, Tanzania. Psychiatry J, 2018:9548471.

Outhred, T., Hawkshead, B.E., Wager, T.D., Das, P., Malhi, G.S. and Kemp, A.H. (2013) Acute neural effects of selective serotonin reuptake inhibitors versus noradrenaline reuptake inhibitors on emotion processing: implications for differential treatment efficacy. Neurosci Biobehav Rev. 37(8):1786-1800.

Schweizer, S., Kievit, R.A,, Emery, T., Henson, R.N. and Cam-CAN (2018) Symptoms of depression in a large healthy population cohort are related to subjective memory complaints and memory perfection in negative contexts, Psychol Med. 48(1):104-114.

Steru, L., Charmat, R., Thierry, B. and Simon, P. (1985) The tail suspension test: a new method for screening antidepressants in mice. Psychopharmacol. 85:367-370.

Vasundhara, S., Ahmad, H. and Rajiv, G. (2013) Memory enhancing effects of Ficus carica leaves in hexane extract on interoceptive behavioral models. Asian J Pharmaceut Clin Res. 6(3):109-113.

Walia, V. (2016) Influence of stress and fluoxetine on immobility period of mice in tail suspension test and 
forced swim test, Asian J Pharmaceut Clin Res. 9(2):302-305.

Walia, V. (2017) Possible role of serotonin and selective serotonin reuptake inhibitors in suicidal ideation and attempts. J Pharmaceut Sci Pharmacol. 1(3):54 -70.

Willner, P. (1997) The mesolimbic dopamine system as a target for rapid antidepressant action. Int Clin Psychopharmacol. 12:1-6

Yu, T., Guo, M., Garza, J., Rendon, S., Sun, X., Zhang, W., et al. (2011) Cognitive and neural correlates of depression-like behavior in socially defeated mice: an animal model of depression with cognitive dysfunction. Int J Neuropsychopharmacol. 14:303-317.
Yusha'u, Y., Adam, U.M, Anave, A.A., Zayyad, U., Wahab, A.A., Saleh, M.J.A., et al. (2019) Chronic administration of alpha lipoic acid shows antidepressant-like effect in mice subjected to chronic mild stress. Nig J Neurosci, 10(2):41-46.

Zarate, C.A., Singh, J.B., Carlson, P.J., Brutsche, N.E., Ameli, R., Luckenbaugh, D.A., et al. (2006) A randomized trial of $\mathrm{N}$-methyl-D-asprtateantagonist in treatment-resistant major depression. Arch Gen Psychiatry. 63:856-864.

Zhang, R., Xue, G., Wang, S., Zhang, L., Shi, C. and Xie, X. (2012) Novel object recognition as a facile behavior test for evaluating drug effects in AßPP/PS1 Alzheimer's disease mouse model. J Alzheimer's Dis. 31:801-812.

Cite as Mustapha, S., Oshafu, M.Y., Adam, U.M., Yusha'u, Y. and Daku, A.B. (2021) Influence of antidepresssant medication on short term memory in chronic mild stress mouse model of depression. Nig. J. Neurosci. 12(1):22-28. http://doi.org/10.47081/njn2021.12.1/003

(c) Copyright Nigerian Journal of Neuroscience. All rights reserved. 